\title{
Starting with Sight: A Conversation between Rosemary Lee and Anna Heighway
}

Rosemary Lee, C-DaRE (Centre for Dance Research), Coventry University

Anna Heighway, Roehampton University

The following is a conversation between Rosemary Lee and Anna Heighway on July 2016, at Alexander Palace, London. The talk centers on Lee's practice, Liquid Gold is the Air (2014), and what it means to be a visual choreographer.

Keywords: choreographic practice, Liquid Gold is the Air, visuality

\section{https://vimeo.com/205526169}

(We sit on wicker chairs, overlooking a garden. Rosemary is looking at me and I am looking at her.)

AH: If you could dance a duet with anybody, dancer, non-dancer, dead or alive-who would you choose?

(Weighs up several partners)

$\mathrm{AH}$ : You can only have one!

RL: Dave Capps.1

$\mathrm{AH}$ : Could you have that dance now? Could you close your eyes, perhaps, and talk us through what unfolds?

$R L:$ (Closes eyes)

Ok. Because he's in America I see him in a chair opposite me, but miles away in a different time zone-with the thought that it might be some sort of a Skype duet. I see a lot of stillness. He's misty because I'm imagining him far away. He's quite small and there is a deep perspective-so it's very cinematic. He's sitting facing me but we can't speak. And there's a sense, that in the stillness, through light or maybe because I'm starting to see him-feel him on screen, rather than feeling you here beside me-of weather and seeing it cross him, of seeing grey clouds and rain come and go again and the light clear, so that he seems more vivid, seems nearer and then seeing him fade again. But I don't see him moving and I don't see myself moving. He can see me with the same thing happening with the weather and light changing. 
$\mathrm{AH}$ : Is there any other sensory information there?

RL: There would be something about the seated-ness and the stillness. I'm becoming aware of my sitting bones, spine and collarbones and I can sense that my elbows are out as if I am about to do something and I'm really aware of that. I'm ready to go (eyes still closed, elbows tense and pushed outwards away from the body) and I'm thinking of that book $\mathrm{H}$ is for Hawk so I'm just going to relax and see-maybe that's the dance. In $\mathrm{H}$ is for Hawk Helen Macdonald talks about the hawk being ready to go at any point. I'm kind of tense enough that I am ready to fly but I don't know where I'm going to fly to and my feet are like talons on a perch but I'm on this wicker chair (smiles) and I feel like he's the same. We are both rooted to the spot but there's all this movement of the elements and probably weather inside us, and maybe this elbow thing. (Opens eyes, laughs)

There we go.

AH: Thanks for that. We met briefly at Bath's opening of Liquid Gold is the Air. In our chat you described yourself as a visual choreographer.

RL: Bit obvious with that task wasn't it? (Laughs)

$\mathrm{AH}:$ What do you mean by 'visual'?

RL: Firstly, I get images in my head like I just did then-quite sort of cinematic. If I'm working in a more site-specific context (Looks out at garden) I would be sitting here and I'd be looking and trying to figure out where the dancer would be-where they might move to in space. Already I'm just looking at it like a kind of a set for figures to be in. In that sense its kind of visual again.

$\mathrm{AH}:$ Have you always experienced things in this way?

RL: Although I was dancing as a child, I was also looking at Renaissance art a lot. I thought an artist was a painter. I wanted to be an artist but as a choreographer. I think I couldn't separate the two in a way.

AH: Is this visual approach manifest in your practice in any other ways?

RL: In Liquid Gold it is fairly obvious, because I've actually made my first triptych. Also, with any site-specific work, I view it in an architectural way. For example, with Under the Vaulted Sky what I'm trying to do for the audience is give them the best view of the site, and this for me was standing looking down the nave. For about two years I was thinking, I've got to give the audience that, but how do I give 300 people that view? That's very manifest in the way that I lead an audience round-that the views that I think are the most stunning and harmonious, dictates how I place people within it, to enhance what you see of the site, but also make sure the dancers look their strongest. 
And I suppose it manifests itself because I make films. The visual side that may have begun as artists being people who painted on a flat canvas, you see in the site-specific work and the film because I'm treating the site or the stage as a canvas. I'm sure everyone is, aren't they? Maybe not.

$\mathrm{AH}$ : That was going to be my next question. I'm wondering what types of choreographic behavior your account of the visual might exclude you from?

RL: Well, I guess for some choreographers it's more about atmosphere or the energy or dynamic. I do think that's very important in my work too, but I'm not so interested in athleticism and what the body can do, especially in terms of extremes-so that's never present in my work. I think some peoples' concern is the plasticity of the body, whereas my concern is the presence of the person in space. Even if I'm making a piece for a hundred people I'm hoping that within the ensemble, which often moves as a flock-that you can also see individuals. That's another thing I'm interested in, individuality and the collective. I think the visual is not the only aspect.

$\mathrm{AH}$ : Undoubtedly. Nonetheless, one of the reasons we are sat here is because of how I felt after watching Liquid Gold is the Air. Four months on, I can't remember what I had for breakfast but I can still recount the shot of the grey-haired women staring at me, grinning, whilst surrounded by flickering gold palms. I've since discovered that there is a moment from every Rosemary Lee work I have seen that similarly snags on my mind. (I describe the moment in boy, when he peeks through a horizontal shape of the arms,2 and a moment from Common Dance when a sea of people floats horizontally across the stage whilst stood on the backs of others, a movement coined 'camel.'s) This got me interested in a possible connection between your ability to create memorable images and the visual nature of your practice.

RL: I am trying to do what you've just described. I'm trying to create images that will burn into your retina, like paintings that stay with you. Exactly what's stayed with you is what I want to stay with you. And it's interesting that you chose that moment from Common Dance because that's a moving image, so it isn't just still figures in space that we are talking about, is it? It's also movement images.

$\mathrm{AH}$ : Are there any choreographers who provide a similar experience for you?

RL: You've reminded me of a work I saw when I was in my twenties in New York in the early 80's by Martha Clarke called Garden of Earthly Delights. I was bowled over by it then. It had Hieronymus Bosch-like images. People became boats and were riding galleons, but in the bodies. In hindsight now I wonder if I might have subconsciously nicked something like 'camel' from there. Her work had these moments that just went ZING and hit you as imagery and those images stayed with you. I love that sort of thing. 
$\mathrm{AH}$ : In an era of visual bombardment, your ability to bring moments to the surface is no small achievement. I'd like to try and understand how you are able to do this. It might help if I could get a clearer impression of the scope of your visuality. What about your initial moments of insight? Do they always present themselves as an image?

RL: (Closes eyes) I had to close my eyes to see, so that means they probably do. Do you see what I mean? I had to do that to get the visual out. It depends. If it's site specific, I'm starting with the site, so I sit there and I look, I don't see things, I don't have a sort of hallucination (Looks out towards garden) but I'd think about where I would put someone-so I am imagining someone still, sitting in a chair there, but l'd also be getting a feel for it. There are lots of things that would be going through my mind. For example, when I went to see the four squares in London for Square Dances, I walked through loads of different squares and would get despondent because nothing would come except a sort of character. I'd get a man in a tail suit and think, That's so typical of me. I can't do that again. Others l'd think, ugghhh, because nothing was coming. And that's to do with the feel of the square as well as the look of it. You can't really pull those apart because whatever the square is, is what's making its mood. There is a mood thing, an atmosphere or vibe too that is part of the insight.

$\mathrm{AH}$ : With the Dave duet you improvised earlier, you went from the visual, to a sort of visual 'feel' of Dave and then into a more somatically orientated awareness of body. Is this a habitual connection?

RL: I think this might link back to my traditional training. In my third year at Laban, I'd been doing Graham and rather hated it. The teaching I'd had was about where your muscles were, counts, action-nothing about the meaning, the dynamic or the sensation and no metaphors. I knew something was lacking. I found it really dry and cold. And then Bonnie Bird had to teach a warm up because the teacher was ill. She got us sitting before we were about to perform and she said "Imagine your ears are like fox's ears" and I thought-now we're talking.4 I've had three years of this and now I know the path I want to follow, I know how I want to work. And that led me into a more somatic practice. I think it's that-that imagery and metaphor is what I use to get people dancing and I only use that: fox's ears, spine like a sea otter's, camel, flock, dissolve, melt, rise, or snap-open like Himalayan Balsam (when the seeds come out)-all of those words are metaphors. The visual into the body is what makes sense to me as a dancer and it's how I teach. I think that's where the body and the visual thing as a choreographer might link up for me.

$\mathrm{AH}$ : You make work for a range of contexts. Does your visual approach change when making screendance work?

RL: Yes. I have more control over what the audience can see and I love that. I can move your eye from boy's mouth chewing the grass, to him as a distant figure in the sand. 
And although I can try and do that with site-specific live work, I can't quite force you to look at it.

$\mathrm{AH}$ : If screendance could be neatly packaged into different genres, which would your films belong to? Feel free to make up a nonsense title.

RL: (laughs) Oh my god-what on earth can I say to that? Something to do with nonverbal connection to landscape? Body and landscape? What would you call that? Poetics maybe-something about poetry I think.

$\mathrm{AH}$ : What would the iconography be?

RL: Close detail and the opposite-where a person is tiny in the landscape, so being very powerful but very humble within the same setting-vulnerable. No speech, elemental on some level-so you feel the weather, you feel the wind and the temperature. Very little artificial light. Strong atmospheric sound-score that enhances the environment you're in and a sense of the presence of the person.

$\mathrm{AH}$ : Could you tell us about Liquid Gold is the Air? How did the work come about?

RL: Under the Vaulted Sky is the live work that took place in the arboretum in Milton Keynes called The Cathedral of Trees.5 I was invited by Milton Keynes International Festival to be an artist in residence. I then did a two-year feasibility study. The reason I was invited was a) they wanted that space animated and b) they wanted to bring more local people into the work of the festival. I was given that site. At the very end of those two years we didn't think we would find the funding for my ambition but The Stables 6 put in a bid for an Arts Council Exceptional Award and we got it. Part of the stipulation of the grant was that they felt that the live work wouldn't reach enough people and that I should make a film as well. I have to say that initially I was very worried about that because I didn't think that I could make a work for a live audience and in my head also be considering shooting a film the day after.

$\mathrm{AH}$ : What was it about that prospect that troubled you?

RL: Well, they are two very different ways of working and they are two different works. They didn't want a documentary-they wanted something that could tour the dance film festivals, so to me initially that looked like a single screen project-a bit like boy or greenman and I knew that this had taken me two years to make. The way I thought I could tackle it in the end is to make an installation that could have a different sense of time and could be really episodic-so that I could just focus on images rather than the progression through with a beginning and an end. Roswitha Chesher-the filmmaker who I invited to collaborate with me on the project-was excited by this concept. And I wanted to make a triptych because Under the Vaulted Sky is set in the Cathedral of Trees and The Cathedral of Trees is set in the footprint of Norwich Cathedral. 
$\mathrm{AH}:$ What does that mean?

$\mathrm{RL}$ : It means that the trees are roughly planted where the pillars would be and the dimensions of the cross of the church are there. If you looked at it from above, you'd see that. The trees become the architecture of the cathedral. I grew up with Norwich Cathedral being the nearest to my home. I loved it as a child. It has the most number of Green Men carved into its roofs. There was a lot of imagery and the thoughts of Norwich Cathedral that came back into the Cathedral of Trees: the icons of early Renaissance art, the gold leaf around the figure, the carvings in the cloisters that have figures that look like they have teeth coming out of them-like images from Mexicowhich is partially where the gold hands around the figures came from, were images that I thought would bring the arboretum to life in the way a cathedral is brought to life. I wanted to add the bling of a Medieval Cathedral to the shaded vernal one.

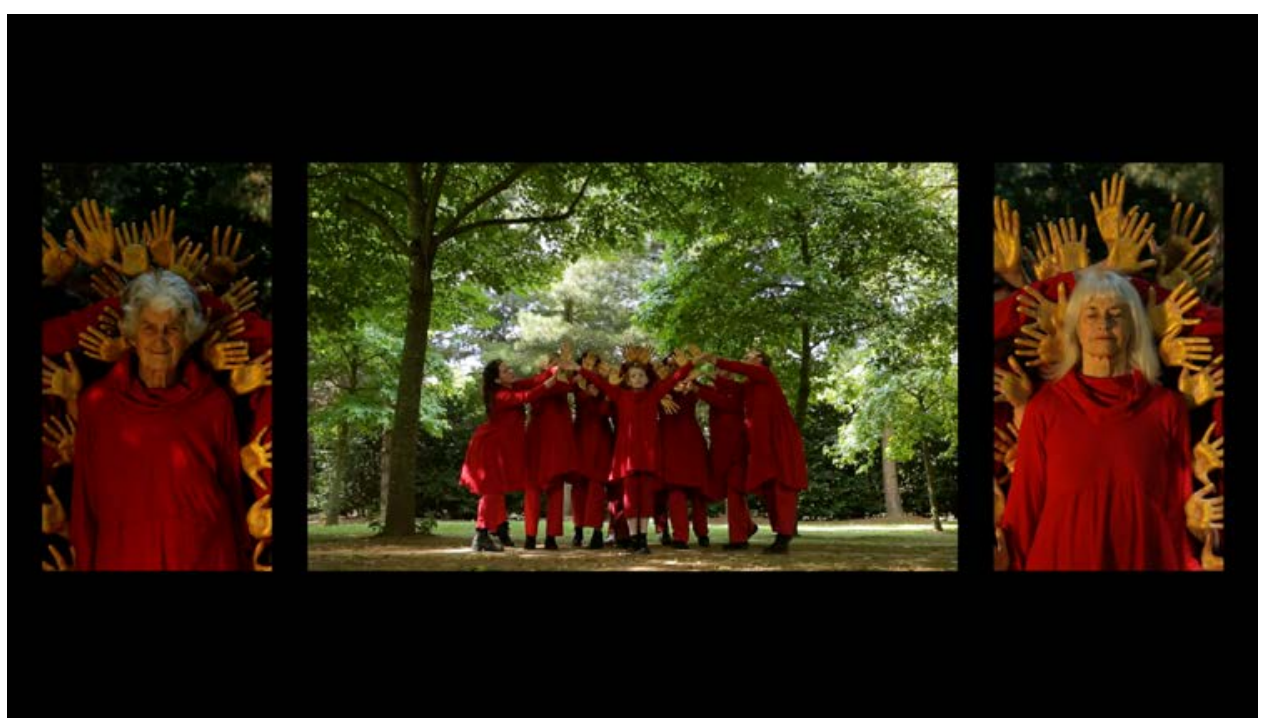

Screenshot, "Liquid Gold is the Air"

$\mathrm{AH}$ : Some people may be surprised by your choice of a multi-screen format as a remedy for lack of time.

RL: (Laughs) Maybe, but also let's not forget that Roswitha had worked with me a lot. She filmed Common Dance brilliantly and made On Taking Care with me so she knows how I work. When I suggested a triptych, she said "What are you talking about, course we can do it." That was great. We could be much more abstract. What she was doingspeaking of visual-was collecting a scrapbook (from Under the Vaulted Sky) of-I want to do that long shot and I'd like the camera here. We could find our favorite shot of the nave for example and we could use it, whereas I couldn't give that to the audience in Vaulted because they couldn't always fit there. It was a joy on some levels because we could look at the site afresh. 
AH: Liquid Gold's status seems complex. Post credits, it's written that Gold is "inspired by" Under the Vaulted Sky. Is it adaptation, documentation, or is it an autonomous screendance work?

RL: I think it's an autonomous screendance work. I think it stands alone. It certainly isn't documentation.

$\mathrm{AH}$ : Is there no duplication between the live work and the installation then?

RL: Well there's definitely lots of stuff that comes from it, but the new context of the installation also transforms it. Adaptation, I think you probably could argue. But again, the works are so different. This business of making another work out of the same inspiration happened with Beached. This was a live piece for three women but I felt that there had been so much imagery, stories, and characters that were resonating with me-that this piece was just one aspect of the foundation and I was feeling frustrated because it felt like it hadn't lived its life properly. Then the wonderful late Niki Pollard 7 who I was working with at that time agreed with me that we should do another Beached, so we wrote a book-it's a book of our notebooks, her questioning of the notebooks and poems-and that's called Beached: A Commonplace Book and that's another work, but it's not an adaptation and it's not a documentation-it's another art form but it comes out of the same roots of the stimulus-of this thing which is imagery, but it's also the whole vibe of it. As I was trying to explain with Gold-this sort of atmosphere: cathedrals, icons, gold, vernal cathedrals, and all the resonance of those ideas and images, I feel like they've come out again but in a new art form.

$\mathrm{AH}$ : When I watched Liquid Gold I was experiencing a transposition of Norwich Cathedral into The Cathedral of Trees on three screens whilst sat in a church in Bathanother complex aspect of the work.

RL: You're right, it is complex and sorting out the copy with it in terms of what you give to people, how you explain it-it's difficult. I also don't want it to be viewed as necessarily religious just because it's in a cathedral. That's very important. It can equally sit in a gallery, a historic building-a meeting room. But I don't think we should shy away from complexity and try to disentangle everything cleanly. In cathedrals there is a rich historical and visual complexity that beautifully reveals the messiness, the over-lapping-ness of a culture. Take the Green Man image-we identify it as folklore, paganism, whatever it is, we don't really know, but the male spirit of nature as opposed to Mother Nature, it's certainly nothing to do with Christianity. I love to think of the skillful people that made those cathedrals carefully carving multitudes of strange creatures-I do enjoy bringing a vernal cathedral into this setting. To have ordinary people in a stand of trees within an alter piece-like context-I feel privileged that all of us who made Liquid Gold is the Air can add something to this continuum of artifact making. 
AH: Let's move on to the soundscape. Was it post-scored?

RL: Yes and we never change an edit-the sound has to fit the visuals. It's complex again because the music for brass instruments and the gamelan sounds-the metallophones music-was the sound composition for the live work by Terry Mann. I realized that music wasn't right for a film installation, so we decided to invite Graham Miller to create a new musical soundscape that incorporated beautiful sections of Terry's music, which we recorded in a large empty church.

$\mathrm{AH}$ : What would Liquid Gold be like without the sound?

RL: Not as dark. Not as suggestive of other green spaces. Not as heightened and intense. Not as suggestive of other elements like fire. There are techniques that he uses within the score like birdsong played backwards and slowed right downbeautiful hidden conceptual ideas that we enjoy together. With Graham it's a really interesting collaboration and he's made all the sound for my work except Snow. He gets my work and intuitively knows exactly what it needs-he realized it for me. We did say we wanted a kind of underlying darkness and that he could add this undercurrent, which I can't always do with my side of the work.

$\mathrm{AH}$ : Why the darkness?

RL: Well, if you don't want to see it, you don't. But then if you plant the suggestionsome people will. For example, with boy, most people see play- they don't see anything dark in it at all, but I showed it to some boys of his age and they all saw it. They were like, "Why is he all alone?" "Why did he jump off the cliff at the end?" "Does he come back?" "Has he killed himself?" I think that with everything in life, you've got black and white and I don't like things that don't allow you not to feel the gamut of the meaning of something.

$\mathrm{AH}:$ I'd like to return to your use of the triptych. It seems to impact on the film in ways that make Gold stand apart from your other works for me. The image is flat, there is no camera movement, very little cutting into moments, so whereas much of your work has that sense of inviting us into and through a world, in Gold it is brought to us, its presented. The visuals belong to the medium of moving images but they register more as pictures.

RL: That's exactly what I wanted.

$\mathrm{AH}$ : I find it interesting that you have used technology to create a sense of archaism. The formality of the Triptych device also draws a distinct boundary line between the viewer and subject that denies the viewer that sense of intimacy that you often capture. Did you have a sense of Liquid Gold's uniqueness in this respect? 
RL: I think that's interesting. I think you're right. I think it is that flatness and because there isn't a narrative leading you towards something of meaning and perhaps it's something to do with time and the fact that it's installation-where in boy you can get drawn into his world in a sense.

$\mathrm{AH}$ : The focus of the subject in Liquid Gold is often directed at us; the audience. Why did you decide to do this?

RL: I am quite interested in people looking directly at you. It's in loads of my work. Infanta does it-she knows you're looking at her. It's in Remote Dancing and in Common Dance. We are doing it now because we are getting used to one another and we're talking, but when I'm giving a talk I can't look at the audience. Maybe it's something about my personal desire for intimacy and my difficulty with that. But it's more than that. I do think that we are reminded of our differences rather than commonality in the media. When I was eight my mum asked me what I wanted for my Christmas present and I said that I wanted this Rembrandt print of this older woman. I had it on my wall when I grew up. It's probably because I loved old people and felt that we were pulled away from them. I loved their wisdom and I loved looking at their faces. I loved the way she looked at me like she looked into my soul. I must have sought that connection with her and I think a lot of my work is about investigating this sense of intimacy that is nonsexual. It's an intimacy that's not about that-it is an intimacy of our souls, our spirits. We are all existing and sharing the same oxygen, and regardless of all the ways we have been brought up there is some unspoken connection. And one other thing I'm trying to give which links back to your memory of Hazel looking at you.8 I grew up with a Quaker background. The maxim of Quakerism-there's no doctrine-but the one thing they might say is that the inner light-the divine-is in everybody. One of the ways you should live your life is to draw out the potential in everybody. You could say that Liquid Gold is about you noticing the inner light in Hazel, and Hazel noticing the inner light in you.

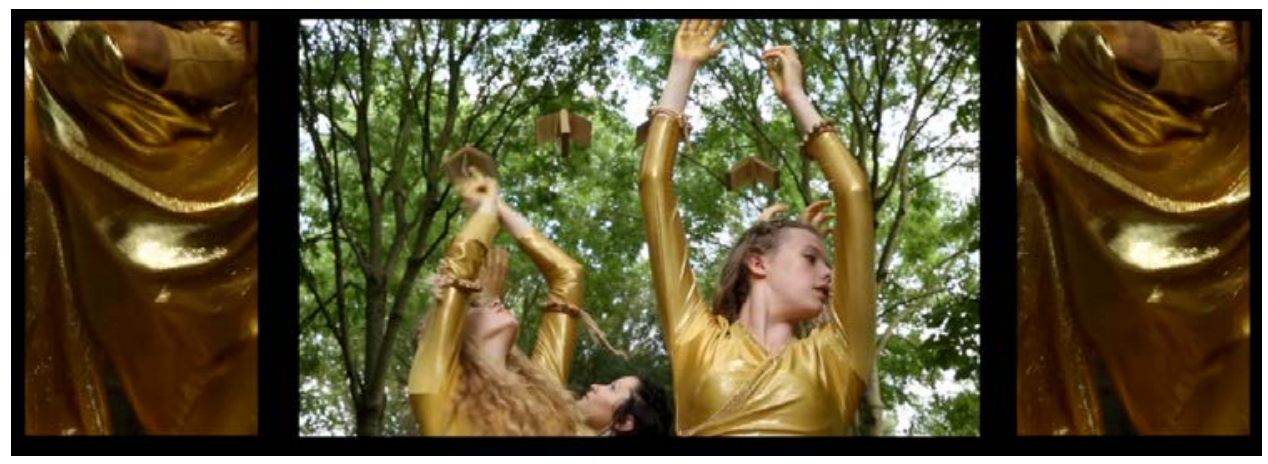

Screenshot, "Liquid Gold is the Air"

$\mathrm{AH}$ : You mentioned earlier, an interest in communicating "the presence of the person in space." There certainly is a sensory quality to Gold that gets beyond the eyes. It's a 
textural, tactile experience. You get the impression of wind on the skin-of the feeling of the performers' experiential connection between motion and site. Despite the distancing effect of image-as-picture, there is a perceptual depth, or at least the impression of it. Let's talk about some of the ways that you achieve this; the first talking point is hands.

RL: There are lots of reasons why I work with hands. I'm working a lot with nondancers. Everybody's hands are expressive and people learn how to use them very quickly. It's practical. The hands suggest people, as feet do-and shoes; they suggest personality. I also use hands because I think that's how we know the world. If you see hands gesturing we must be suggesting something about the rest of the world and our knowledge of it-because that's how we know-we touch. I'm reminded of the line From Michael Donaghy's poem, Touch: "She touches my hand to know ..."9

$\mathrm{AH}$ : And the dancers, how am I experiencing such a strong sense of them 'experiencing-the-experience' if you like?

RL: Well I think this comes from a link between the somatic side of what I'm trying to get the dancers to experience and what I'm trying to do in the film. For example the only way I will teach movement is through imagery and through them sensing that image-so its felt. They always work with their eyes closed. Although I'm a visual choreographer the first thing I do, is take away the visual from the experience of the dancer. They must imagine and embody that image. We always use touch-it's all through skin. It's hands on, and moving with the hands-pushing into the space. Seeing them do this helps you as the viewer, move into your own body-so as well as wanting to create something imagistic as you say, I'm wanting people to sense their bodies more present in the space at the moment of watching. It's also because of the simplicity of the images. They're opening their arms to the sky, they're listening, they're swaying-the leg isn't up by the ear-you (the audience) immediately feel that you could be there doing that, so then it puts you in the dancer's body and you start feeling your own body.

AH: Time also lends a 'felt' quality to Gold. The pacing is steady-there's temporal space allowed for images to unfold. It's practically palpable-you could sink your teeth into it.

RL: I think you're right-time does allow for a more haptic response. And I can allow for time with an installation, with a five minute film it's harder. If you don't give yourself time to taste something you will always skim it. If you allow it to unfold at a certain pace and you give people time, their heart rate will probably slow a bit. I think it does happen with Gold-people do leave in a different state, like they've had a meditative experience, and this means they'll see in a different way-I mean 'see' in all senses. They'll sense in a different way. 
$\mathrm{AH}$ : There is also a sense of 'otherworldliness,' of things being more than they seem in your work. People apparate then dissolve, they move in reverse, they can walk through the confines of the frame-like ghosts walking through walls. Where is this coming from?

RL: Mystical experience-I'm really interested in what that is. As a child, I wanted to see an angel-I wanted to sense one. I desperately wanted to believe that there was more out there than the grit of the ordinary day-to-day-more than the familiar world. I sensed the world a bit like boy is sensing the beach. I think I was very dreamlike as a child so that's all in there. I mean I'm not Christian with a belief system but I think I'm quite spiritual-whatever that might mean-who knows. With Liquid Gold, there's also something else going on because if you make people appear and disappear you are also suggesting death and life. boy was more about magic, but in Gold, where they fade in and out, it might suggest 'Dust to dust' and 'Ashes to ashes' as well. They are magical but they're also real. As well as the reality of eye-to-eye, skin-to-skin in the present moment, I want to remind people that life isn't permanent. I know that sounds very cruel but I feel it's quite important that we treasure it more, but also that we don't have that hubris-that arrogance of permanence-because we are like a fleck of dust. It's about the mystery of life but also the grittiness and holding those two things together at once. The sense of permanent impermanence, the vitality of life and the closeness of death, the feeling of death when you give birth, or the feeling of birth when you die-all of those passages. I think those are the mystery-that's the mystical bit that is so extraordinary, so I suppose I'm trying to get a little flavor of that.

\section{Biographies}

Rosemary Lee is known for working in a variety of contexts, Rosemary has created large-scale site-specific works with cross-generational casts, solos for her-self and other performers as well as video installations and short films. Her work is characterized by an interest in creating a moving portraiture of both individuals and of the close performing communities she brings together. Regardless of the scale of these projects she creates a unique intimacy with her audience whilst also exploring and highlighting our relationship with our environment. Rosemary also writes, guest teaches and lectures internationally. Recipient of both a Bonnie Bird Award and a Jerwood Choreographic Research Project Award in 2013, she is an Artsadmin Artist, a Work Place artist, a DanceEast Artist Associate 2015, a Senior Research Fellow at CDaRE Coventry University, a ResCen Research Associate Artist (Middlesex University) and holds an honorary doctorate from Roehampton University. 
Anna Heighway is a Dance Artist and Lecturer currently living in Bath. Many years spent studying dance and film alongside a career in television is reflected in the breadth of her practice. Anna is currently studying for a PhD in screendance practice and philosophy at Roehampton University.

Email: a.heighway@bathspa.ac.uk

\section{Notes}

1 David Capps is Associate Professor at Hunter College, New York City. He and Rosemary danced together when she lived in NYC in her early 20's. At 6ft 4in, he was one of the few people who could help her 'fly.'

2 boy, Lee and Anderson.

3 Common Dance, Lee.

4 Bonnie Bird was a dancer with the original Martha Graham Company. She became Director of the Dance Theatre Department at Trinity Laban in 1974.

5 The Cathedral of Trees was designed by landscape architect Neil Higson in 1986 and is planted in the outline or 'footprint' of Norwich Cathedral.

6 The Stables is a live music venue based in Milton Keynes. It also initiated and funds The Milton Keynes Festival.

7 Niki Pollard was a writer and researcher who worked closely with Rosemary on a number of projects. http://www.rescen.net/archive/n_pollard.html\#.V7TV-4RluCQ ${ }_{8}$ See the late Hazel Powell in the first screenshot, far left. 9 Michael Donaghy, "Touch."

\section{References}

Beached. Chor. Rosemary Lee. Perf. Ch4pter. UK, 2001. Site-specific live.

boy. Dir. Rosemary Lee and Peter Anderson. Chor. Rosemary Lee. London: MJW Productions, 1995. Film.

Common Dance. Chor. Rosemary Lee. UK, 2009. Live work.

Donaghy, Michael. "Touch." Michael Donaghy: Collected Poems. London: Picador, 2014. greenman. Dir. Rosemary Lee and Peter Anderson. Chor. Rosemary Lee. London: MJW Productions, 1997. Film. 
Infanta. Dir. Rosemary Lee and Peter Anderson. Chor. Rosemary Lee. London: MJW Productions, 1998. Film.

Lee, Rosemary and Niki Pollard. Beached: A Commonplace Book. London: Rescen Publications, 2006.

Liquid Gold is the Air. Dir. Rosemary Lee and Roswitha Chesher. Chor. Rosemary Lee. UK, 2014. Film.

Macdonald, Helen. H is for Hawk. London: Vintage, 2014.

On Taking Care. Chor. and dir. Rosemary Lee. UK: Rescen Publications, 2012. DVD.

Remote Dancing. Chor. Rosemary Lee. Dev. Nick Sandiland. UK, 2004. Installation.

Snow. Dir. Rosemary Lee and David Hinton. London: Arts Council/BBC, 2003. Film.

Square Dance. Chor. Rosemary Lee. UK, 2011. Live work.

The Garden of Earthly Delights. Chor. Martha Clarke. USA, 1984. Live work.

Under the Vaulted Sky. Chor. Rosemary Lee. UK, 2014. Live work. 